\section{Comment on: Determinants of bone mineral density through quantitative ultrasound screening of healthy children visiting ambulatory paediatric clinics}

\author{
To the Editor
}

I have read with interest the study by Al-Agha et $\mathrm{al}^{1}$ published in June 2019 issue of the Saudi Medical Journal. The authors studied the determinants of bone mineral density (BMD) through screening healthy Saudi children using a quantitative ultrasound (QUS). They found a significant association with BMD during first 2 years with height $(p=0.015)$, breastfeeding $(p=0.025)$, and vitamin $\mathrm{D}$ supplementation $(p=0.03)$. They also found a directly proportional relationship with BMD with pubertal status, diet, physical activity, sun exposure, and calcium supplement intake. ${ }^{1}$ Apart from the 2 study limitations addressed by the authors, I assume that the following methodological limitation might additionally cast suspicions on the accuracy of the study results. In the methodology, the authors mentioned that the recorded speed of sound (SOS) value was converted to a $\mathrm{Z}$ score using the manufacturer's data bank for age and gender matched SOS values for the left (SOS-L) and right (SOS-R) radii. Participants were regarded to screen positively for osteoporosis if their recorded $\mathrm{Z}$ score was -2 or below. ${ }^{1}$ It is explicit that the precise evaluation of BMD in a given pediatric population requires the employment of population-specific QUS reference values (RV) for age and gender. In fact, QUS BMD normative values have been constructed for certain pediatric populations. ${ }^{2-5}$ Evaluation of various QUS BMD RV revealed noticeable differences in SOSRV in different pediatric populations. ${ }^{6}$ Therefore, the construction of Saudi QUS BMD RV deems essential and the employment of that national RV in the clinical fields and researches could yield a better idea on bone health status in the Saudi pediatric population

Mahmood D. Al-Mendalawi Department of Paediatrics Al-Kindly College of Medicine, University of Baghdad Baghdad, Iraq

\section{Reply from the Author}

No reply was received from the author.

\section{References}

1. Al-Agha AE, Kabli YO, AlBeiruty MG, Milyani AA. Determinants of bone mineral density through quantitative ultrasound screening of healthy children visiting ambulatory paediatric clinics. Saudi Med J 2019; 40: 560-567.

2. Baroncelli GI, Federico G, Vignolo M, Valerio G, del Puente A, Maghnie $M$, et al. Cross-sectional reference data for phalangeal quantitative ultrasound from early childhood to young-adulthood according to gender, age, skeletal growth, and pubertal development. Bone 2006; 39: 159-173.

3. Christoforidis A, Papadopoulou E, Dimitriadou M, Stilpnopoulou D, Gkogka C, Katzos G, et al. Reference values for quantitative ultrasonography (QUS) of radius and tibia in healthy greek pediatric population: clinical correlations. J Clin Densitom 2009; 12: 360-368.

4. Gonçalves EM, Ribeiro RR, de Carvalho WR, de Moraes AM, Roman EP, Santos KD, et al. Brazilian pediatric reference data for quantitative ultrasound of phalanges according to gender, age, height and weight. PLoS One 2015; 10: e0127294.

5. Szmodis M, Zsákai A, Bosnyák E, Protzner A, Trájer E, Farkas A, et al. Reference data for ultrasound bone characteristics in Hungarian children aged 7-19 years. Ann Hum Biol 2017; 44: 704-714.

6. Rivas-Ruiz R, Méndez-Sánchez L, Castelán-Martínez OD, Clark P, Tamayo J, Talavera JO, et al. Comparison of International Reference Values for bone speed of sound in pediatric populations: meta-analysis. J Clin Densitom 2016; 19: 316-325. 